Canada, Ltd. Deep River, the residential area for employees, is some ten miles from the plant and its position is isolated, 130 miles north-west of Ottawa and 28 miles from Pembroke. The comforts of modern civilization are well provided, but, as Miss Kinsey points out, the comparative geographical remoteness and disadvantages of a closed community engaged exclusively on secret work are factors which, though not by any means of over-riding importance, should be well borne in mind by those contemplating going from Great Britain to work at Chalk River.

\section{Rate of Accretion of Matter by Stars}

A very comprehensive investigation of the problem of the development of massive stars from less massive ones by the accretion of interstellar matter is given by Prof. W. H. McCrea in a paper entitled "The Rate of Accretion of Matter by Stars" (Mon. Not. Roy. Astro. Soc., 113, 2 ; 1953). An elementary quantitative investigation suggests that under normal conditions for stars and interstellar space the theory is very improbable, but this does not imply that the processes envisaged by the accretion theory do not occur in exceptional cases. The accretion of a large amount of their material in recent astronomical times is required by only a minute fraction of all the stars, and in these circumstances the conditions required are not so improbable as they might appear to be. It is shown that massive stars can be produced from less massive ones by the accretion process if the motion of the star is halted by the interstellar matter, and this can take place if the initial speed of the star relative to this interstellar matter is sufficiently low. Recognizing that the occurrences must be rare, it is shown in the paper that all the necessary requirements are to be found in the Galaxy, and in addition, assuming that the phenomena actually occur, the demarcation between the stars affected and those not affected must be quite sharp, owing chiefly to the sensitivity of the effects to the velocity factors. Having accounted for the mass increment, the question arises whether the theory can also account for its production at a rate that ensures its adequately compensating the transmutation of hydrogen in the stars under consideration. An investigation of this subject shows that no difficulty arises in this way. Regarding the applicability of the theory, it is admitted that the heating effect of the radiation from the star upon the neighbouring cloud material appears to be ignored. It is pointed out, however, that this effect is expected at most to enter at some stage when the star has attained a great luminosity, to produce a cut-off effect; otherwise the application in principle of the theory does not seem to encounter any serious obstacle. The main problem now is to endeavour in some way to estimate the actual frequency of occurrence of the processes.

\section{Glacial Eustasy and the Rotation of the Earth}

A PAPER by Andrew Young, entitled "Glacial Eustasy and the Rotation of the Earth", deals with the causes of secular deceleration of the earth's rotation and the consequent acceleration of the moon (Mon. Not. Roy. Astro. Soc., Geophys. Supp., 6,7 ; June 1953). It is shown that glacial eustasythe rise and fall of sea-level due to the release and absorption of water in glaciated regions-may be responsible for changes in the moment of inertia of the earth, but not if complete isostatic compensation occurs. Following deglaciation of a given region, isostatic compensation results in an up-doming of the crust which formerly carried the ice load; but this isostatic compensation occurs at a very much slower rate than the regression or advance of the ice-sheet. In addition, it seems to take place only when a minimum change in the surface load is exceeded, and is non-existent with minor glacial fluctuations. For these reasons, changes in sea-level produced by glacial conditions are attended by immediate changes in the moment of inertia of the earth and then followed by a slower compensatory change of opposite sign. Climatic and glaciological considerations indicate that fluctuations of sea-level occur, and these can contribute significant amounts to the secular acceleration of the moon. Changes in tidal friction due to a rise in sea-level are shown to have been very small and could not be responsible for the moon's apparent acceleration. There is fairly good evidence that there is a rise in sea-level at present, in consequence of which tidal friction is changing, but only slightly.

\section{An Oil Palm Journal}

Tre Director and Staff of the West African Institute for Oil Palm Research are to be congratulated on the interesting contents and pleasing format of the first number of their Journal. The Journal can be purchased from the Institute, near Benin City, Nigeria, or from the Crown Agents for the Colonies, 4 Millbank, London, S.W.1 ; price 2s. 6d. The inception, development, organization, staff, aims and achievements of the Institute are described by the director, Mr. F. W. Toovey. A long article by Dr. J. M. Waterston deals with the origin and history of Nigerian palmeries, the effect of ecological factors on the incidence of disease, and the major diseases thus far reported. An important feature of this article is a check list of the bacteria, slime moulds and fungi recorded on the African oil palm. The controlled pollination of the oil palm is described and illustrated by $\mathbf{M r}$. C. Purvis, while more strictly agricultural matters, such as the field planting of palms, methods of germinating seed and the establishment of nurseries, are also dealt with in several articles. In this first number the editorial aim-to record the research work of the Institute and to extend the scientific knowledge of the oil palm as a plant and a crop-has undoubtedly been given a good start.

\section{Stability of Living Organisms}

The stability of complex organic substances synthesized by living organisms is of great theoretical and practical importance. One aspect of this problem, namely, the stability of biological substances that can be expressed in terms of the time during which these substances will retain their specific biological properties and, therefore, the integrity of their structures, has been examined by Prof. D. Keilin (Sci. Prog., 41 ; October 1953). The problem is first considered with regard to the stability of biological materials in vitro and then in vivo. Finally, the stability of the whole complex structure of a living organism is discussed, especially when its metabolic processes are at their lowest ebb, when they are scarcely perceptible or even when the organism is in a state of anabiosis.

\section{Population Council, Inc.: Fellowships for Advanced Training}

A N⿴囗十 organization, the Population Council, Inc., has recently been established in the United. States as a non-profit corporation in order to encourage research 